\title{
Key Opportunities for China to Lead Globalization 3.0
}

\author{
James Chang
}

\begin{abstract}
Globalization 3.0 has gradually arrived over the last couple of years, mainly focused on information, data, technology, and finance, characterized by a high-level of technological exchange based on data and information. With China forecasted to generate more data than any other nation in the world by 2025 and its strides in becoming a digital nation, China and its enterprises will likely play a proactive role in promoting this new era of globalization. China will also influence supply chains and sustainable development to combat climate change. Finally, China's efforts to create a balanced data asset ecosystem ultimately make it poised to play a part in shaping this exciting new era.
\end{abstract}

Keywords Globalization 3.0 $\cdot$ Digital nation $\cdot$ Supply Chains $\cdot$ Sustainable development $\cdot$ Climate change $\cdot$ Data asset ecosystem

\section{Introduction to Globalization 3.0}

Many believe that due to US-China trade tensions and tech war, coupled with COVID19 and its disruption to global trade and other economic activities, de-globalization is an inevitable trend. This depends on how globalization is defined. Our view is that there is sufficient reason to believe a new era of globalization has come. And China, along with Chinese enterprises, has a unique opportunity to be in the driver's seat to lead the world in bringing forth this new wave of globalization.

\footnotetext{
(C) 2021 PwC. All rights reserved. PwC refers to the PwC member firms in China, the PwC network and/or one or more of its member firms, each of which is a separate legal entity. Please see http:// www.pwc.com/structure for further details.

Disclaimer: The information contained in this article is for reference only. It is not intended to be comprehensive and does not constitute legal, tax or other professional advice or service by PwC. No PwC member firm is responsible for any loss caused by any party's use of the content in this article.
}

J. Chang $(\bowtie)$

PwC China, Shenzhen, China

H. Wang and L. Miao (eds.), Transition and Opportunity, China and Globalization, https://doi.org/10.1007/978-981-16-8603-0_9 
The rate of change in the world has and will only continue to accelerate. Beginning only 30-40 years ago, with walls falling down, the warming of cold wars and declarations of a "new world order", we believe that Globalization 1.0 as we define it in the modern era, began around the turn of the new millennium and lasted about a decade. This era was mainly based on the trade of products and the exchange of goods. This chapter of globalization was expedited with China joining the World Trade Organization in 2001, and gradually establishing itself as the world's factory. Importing and exporting were based on the comparative advantage of each country, and countries involved all benefited from this exchange of products.

The era of Globalization 2.0 was mainly concerning the movement of people. We noticed three main reasons for people to go overseas. Some went to pursue an education, some traveled to access high-quality medical resources, and others went for tourism and cultural experiences. People exchanged their consumer power for educational, medical and cultural resources. This era of globalization also lasted for about 10 years until about 2020 .

We believe Globalization 3.0 has gradually come into its own over the last couple of years. This wave of globalization is mainly focused on information, data, technology and finance, characterized by a high level of technological exchange based on data and information.

With the explosion of data in this digital age, we see the future in the hands of whoever controls data algorithms and the global exchange of information. Chinese technology companies such as Huawei. Despite being subject to sanctions by the US, companies like Huawei have made impressive progress internationally over the years, establishing themselves as world leaders in 5G technology, fiber-optic networks, equipment for cellular networks, and smartphones. Xiaomi products are present in more than 90 countries and regions around the world, as stated on its website, and have a leading position in many smartphone markets including India. Chinese tech companies have noticed and caught on to this trend and have been gaining traction in recent years.

Against the background of China's Dual Circulation Strategy announced in 2020, China is looking to actively promote domestic and foreign demand, import and export demand, coordinate between attracting foreign capital and making foreign investments, and attempt to balance international payments. Additionally, with China forecasted to generate more data than any other nation in the world by 2025 , along with the strides it has been making to become a digital nation, this creates significant opportunities for China and its enterprises to play a proactive role in promoting this new era of globalization. We see three key themes developing in Globalization 3.0, namely the reshaping of global supply chains, promoting sustainable development and combating climate change, and building a balanced data asset ecosystem. This article will attempt to elaborate on these key themes and provide insights into the opportunities within. 


\section{Reshaping of Global Supply Chain}

China is no longer just the world's provider of low-cost products, which is what it was known for during Globalization 1.0 after it joined the WTO in 2001. Diminishing of competitive advantage, including lower labor costs, a devalued RMB and lower export tax rates, means that China gradually lost its edge against other low-cost nations of the world. Since 2015, China has made ambitious plans to implement industrial upgrades by enhancing the quality of its products and equipment with a greater emphasis on technological innovation and R\&D. In fact, China's goal is to spend $2.5 \%$ of its GDP in this sector by 2020, as spelled out in its 13th FiveYear Plan. In 2019, the National Bureau of Statistics reported that total spending in public and private science and technology rose $12.5 \%$ over the previous year to RMB 2.21 trillion (USD 322 billion), amounting to $2.23 \%$ of GDP. In the recently announced 14th Five-Year Plan, Chinese policymakers emphasized increasing R\&D spending with the government leading the way as well as providing tax incentives for businesses that invest in basic R\&D. For many years now, companies that spend over a certain amount in R\&D have been classified as "high-tech", which could give them a $10-15 \%$ reduction in corporate income tax.

All these efforts have been part of China's attempt to move upstream over the years by manufacturing mid- to high-end products with relative technical advantages in the industrial chain. This has been accomplished through product upgrades, including in supply chains, in order to participate more deeply in higher margin and higher value-added sectors including technology hardware, hi-tech machinery, healthcare equipment and products, as well as automotive and auto parts. As a result, some relatively low value-added, labor-intensive industries such as the textile industry and furniture manufacturing industry have moved to countries with lower labor costs and more flexible, if not absent, environmental protection regulations. Any manufacturing sector that has lower barriers to entry, simpler operational requirements and is easier to replicate is ripe for similar transfers. Furthermore, local Chinese companies are taking over market shares from multinational companies in industries like home appliances, smart phones and construction machinery. This includes cases of divestment of business units to Chinese companies, contract manufacturing being dominated by Chinese companies and MNCs offshoring their ecosystems to other countries.

China has been helping facilitate this transition by actively involving ASEAN nations and other nations in supply chains, which was expedited by the signing of the Regional Comprehensive Economic Partnership (RCEP) agreement in November 2020. This will be the world's largest free trade agreement in terms of combined GDP (USD 26 trillion), population (2.27 billion) and total export value (USD 5.2 trillion). ${ }^{1}$ China's foreign direct investment (FDI) into ASEAN nations has been growing annually at $15 \%$ in recent years and ASEAN has surpassed the EU to become

\footnotetext{
${ }^{1}$ PwC CN, November 2020. RCEP successfully signed. https://www.pwccn.com/en/tax/publicati ons/rcep-news-alert-nov2020.pdf.
} 
China's largest investment region, receiving $42 \%$ of its FDI in $2018 .^{2}$ Furthermore, the Belt and Road Initiative launched in 2013 has been facilitating regional and global cooperation and is reshaping the global value chain. China has now become the biggest trading partner and the biggest destination for exports and FDI for 25 Belt and Road countries. China will be able to continually increase its ability to leverage its own industrial capacity, capabilities, ecosystem of quality resources and management know-how to create synergies with cutting-edge technologies from Europe and beyond. The pandemic acted as an accelerator for domestic and foreign manufacturers to rebalance their supply chains and manufacturing through a "China Plus One" strategy, which may be beneficial for China as more capacity has become available for higher value-added products in the value chain.

This industrial upgrade was not only a decision made so that China would depend less on exports, as was the case since Globalization 1.0, but also a decision that would increase average per capita income in China and reinforce consumption upgrades. China's measures to promote supply-side reform and urbanization in recent years have been strategic moves to continuously release the potential of its domestic demand. We believe China's domestic consumption market will soon overtake the United States to be the largest in the world, with huge upside potential. China's enormous domestic market and the increasing middle class has been attracting MNCs to adopt an "In China, For China" strategy, in which manufacturers are directing their focus towards primarily selling to the China market instead of exporting. This strategy is used predominantly for industries that are less prone to be affected by US-China decoupling, including consumer products, retail, consumer health, hospitality, entertainment and education. In fact, according to an AmCham Shanghai survey from November 2020, $82 \%$ of US companies operating in China surveyed showed no intention of relocating their manufacturing facilities out of China over the next three years. China's robust supply chain and huge domestic market make it a resilient hub to build a supply chain strategy around and is a difficult one to walk away from.

In recent years, China has digitalized significantly across industries. COVID19 has accelerated the drive by manufacturers in China to digitalize and increase automation to build resilience and truly connected local supply chains that can withstand external shocks. This required more agile and efficient supply chain solutions and tools covering sales enablement, planning and forecasting, smart manufacturing and digitized warehousing and logistics networks. For example, there is increased investment in areas such as data-driven sales forecasting or AI-based algorithms that can now be applied to demand planning. With no immediate end to the global pandemic in sight, automation will be vital both in increasing supply chain and production efficiency, as well as helping to mitigate safety measures in factoriessuch as social distancing-through the use of robotics. Furthermore, to promote greater transparency across supply chains in China, more companies are looking to place the right data and analytical tools that provide visibility across the chain

${ }^{2} \mathrm{PwC}$ CN, September 2020. ASEAN Countries with Overseas Investment Opportunities. https://www.pwccn.com/zh/research-and-insights/asean-countries-with-overseas-investmentopportunities-gba-sep2020.pdf. 
for alerts, detecting issues, providing insights on availability, utilization as well as enabling integrated materials planning. Enterprises that were more advanced digitally and had greater operational flexibility, have constantly outperformed in China since the pandemic, especially those with strong business continuity plans. In addition to the digitization of the core supply chain, back-office shared services such as finance, HR, technology, procurement, and marketing are all experiencing a drive towards more automation, digitization and virtual technology.

In a sense, we see this trend of digitalization as an accretive opportunity for China to lead the world in an era of Globalization 3.0 as it reshapes the global supply chain. With the huge amount of data generated in China and by Chinese companies overseas every day, under an agreed-upon framework for data protection and cybersecurity, the fuel for globalization is available for nations involved to mutually benefit from this deeper level of exchange.

\section{Sustainable Development and Climate Change}

Sustainable development was first incorporated into the long-term strategy of China's economic and social development in 1992, following the Rio Declaration on Environment and Development with sustainable development as its core concept, raised by the United Nations the same year. Fast forward to 2015, the United Nations introduced 17 Sustainable Development Goals (SDGs) in "Transforming our world: the 2030 Agenda for Sustainable Development", including goals such as sustainable economic growth, combat climate change, quality education, ending poverty and so on. Sustainable development has become a key trend in globalization as it addresses a global issue that impacts every nation and every being.

China has been a pioneer in integrating sustainable development within its national development plans and government policies, helping accelerate the progress towards achieving the SDGs. Currently, China ranks 85 th globally in terms of the human development index (HDI) and is the only country to have moved from low to high in the human development category. ${ }^{3}$ Over the last 40 years, China has lifted over 750 million people out of poverty and officially announced its victory over extreme poverty at the end of $2020 .^{4}$

China has also made significant strides in improving education and health, with the average years of schooling increasing from 8.8 to 13.9 since 1990 and life expectancy increasing from 69 to 76 years over the same period. ${ }^{5}$ Furthermore, since 2016, SDG pilot zone cities have been designated by the government for sustainable innovation. The country has also grown into its role as a global development partner by helping

\footnotetext{
${ }^{3} \mathrm{PwCCN}$, July 2020. Private Sector Awareness of the Sustainable Development Goals. https://www. pwccn.com/en/services/consulting/publications/private-sector-awareness-of-the-sustainable-dev elopment-goals-jul2020.html.

${ }^{4}$ Same as above.

${ }^{5}$ Same as above.
} 
other countries in their pursuit of the SDGs through international cooperation and development assistance. In China's 14th Five-Year Plan, the absence of specific GDP targets has signaled that the nation is moving towards a focus on higher quality and more sustained economic growth.

In December 2015, the Paris Agreement was signed by about 200 nations with commitments to substantially reduce global greenhouse gas emissions and to limit the global temperature increase in this century to $2^{\circ} \mathrm{C}$ or even down to $1.5^{\circ} \mathrm{C}$. In September 2020, the President of China, Xi Jinping, announced at the UN General Assembly the nation's commitment to reach peak carbon levels by 2030 and achieve carbon neutrality by 2060, upgrading China's independent contribution to the Paris Agreement. This is the greatest climate commitment by any country so far to reduce expected global warming, and the nation's leadership is confident that it will reach this goal. "Doing a good job in peaking carbon dioxide emissions and carbon neutrality" is part of the eight key tasks for the nation in 2021 as decided at the Central Economic Work Conference in December 2020. A month later, the People's Bank of China listed the execution of carbon peaking and carbon neutrality as one of its ten key tasks in 2021, emphasizing the enhancement of "the financial system's ability to manage climate change related risks".

According to research by Tsinghua University, China must adopt a $1.5^{\circ} \mathrm{C}$ emission reduction path to achieve its target of carbon neutrality by 2050 , and steep emission reductions must start now. Practically speaking, China must speed up the adjustment and optimization of its industrial and energy structures, work to peak coal consumption as soon as possible, vigorously develop new energy and accelerate the establishment of national trading market for energy usage rights and carbon emissions rights. Additionally, continuous efforts in combating large-scale pollution, reducing carbon and other pollutants and expanding green land are required to enhance the ecosystem's ability to absorb carbon.

Beyond the environmental benefits, adopting green practices makes business sense. Making energy systems greener could boost global GDP by USD 98 trillion by 2050, delivering 2.4\% more GDP growth than current plans. By boosting investments, the number of renewable energy jobs could quadruple to 42 million globally in the next 30 years, with healthcare savings eight times the cost of the investment and helping to prevent future crises. ${ }^{6} \mathrm{Six}$ million jobs can be created by embracing the circular economy, where used goods are re-used, recycled and upcycled at a greater value. And 1.2 billion jobs- $40 \%$ of all jobs on earth-depend on a healthy and stable environment. ${ }^{7}$

It is estimated that by 2030, SDG-generated economic growth could reach USD 12 trillion, or $10 \%$ of the current global GDP, of which China could account for

\footnotetext{
${ }^{6}$ https://www.irena.org/newsroom/pressreleases/2020/Apr/Renewable-energy-can-support-resili ent-and-equitable-recovery.

${ }^{7}$ https://www.ilo.org/weso-greening/documents/WESO_Greening_EN_web2.pdf.
} 
USD 2.3 trillion. $^{8}$ At the enterprise level, based on PwC's recent survey report on Business and Sustainability in China, Chinese enterprises have taken an active part in putting SDGs into practice with $71 \%$ stating they have pursued practical actions to do so. ${ }^{9}$ Many companies believe that implementing SDGs can increase their brand value and improve their competitive advantages. Corporate willingness to closely combine SDGs with strategy and business has increased noticeably in China, along with demand for pro-SDG programs.

Against the backdrop of Globalization 3.0, we believe that Chinese businesses should focus on building various partnerships to apply the SDGs. Partnerships include both stable business partners at home and abroad as well as cooperation between upstream and downstream industries. Globally, international cooperation in science, technology and innovation can raise the industrial threshold, thus pushing all sectors forward towards achieving SDGs. Leading market players can also bring enterprises together and advocate partnerships for the whole industry.

While awareness of the SDGs and related activities have improved, some challenges still remain in China's journey towards sustainable development. Our survey shows that nearly $42 \%$ of companies have no idea how to evaluate the SDGs. Chinese enterprises should reflect on how to evaluate the effectiveness of prioritized SDGs and how to leverage the influence of existing projects. Additionally, PwC's global surveys show that $72 \%$ of companies have mentioned the SDGs in their annual reports and sustainability reports. $50 \%$ of companies surveyed believe that the SDGs are critical to their business and should be prioritized. On the China side, the numbers have been rising with $55 \%$ of companies surveyed publicly disclosing their sustainable development practices, mainly driven by external regulatory requirements. As China's practice of sustainable development gains momentum, state-owned enterprises that are heavily influenced by government policies show a higher disclosure rate at $67 \%$, while privately owned enterprises lag behind with only $45 \%$ disclosure. $^{10}$

As China marches towards its 2060 carbon neutral commitment, more and more companies across industries will disclose SDG practices and align their company's strategy with sustainable development. As the world's largest economy according to the IMF, based on purchasing power parity, and the world's largest developing nation, China's leadership role in Sustainable Development and Climate Change will no doubt impact the world and become a central theme in Globalization 3.0.

\footnotetext{
${ }^{8} \mathrm{PwC} C \mathrm{~N}$, July 2020. Private Sector Awareness of the Sustainable Development Goals. https://www. pwccn.com/en/services/consulting/publications/private-sector-awareness-of-the-sustainable-dev elopment-goals-jul2020.html.

${ }^{9}$ Same as above.

${ }^{10}$ Same as above.
} 


\section{Data Asset Ecosystem}

Over the past decade, the development of the mobile internet has led to an exponential accumulation of data, which is an essential resource in the digital era. As the value of data is evolving into a deeper level, data is becoming more like water and air which is indispensable in our daily life, as opposed to the general consensus that data is the "oil" of the digital era. Without the support of data, our daily life and productivity at work would not be able to function well in this modern world. Therefore, it is of global interest to unlock the value of data by creating a balanced data asset ecosystem.

Data as an asset is an emerging concept. Similar to commodities, data can be sold, transferred and applied. From an economic and legal perspective, all assets must have three core characteristics. First of all, an asset should have clear ownership. However, with the unique nature of data, there may be multiple owners of a data asset, which leads to ambiguity. Secondly, an asset should be able to generate expected economic benefits. There needs to be a reasonable pricing mechanism for data assets to generate economic benefits. However, the pricing of data assets depends on specific scenarios in which it is used, which leads to variations in pricing. Thirdly, an asset should be a scarce resource. Due to the fact that data assets are artificially created resources, they may have an inexhaustible supply.

China has the opportunity to lead the world in building a balanced data asset ecosystem by addressing the issues mentioned. In June 2019, the Data Asset Evaluation Index System for E-Commerce was officially released under the leadership of the China National Institute of Standardization. As the first official document related to data assets released by the state, the index system fills the standard gap in data assets in China and reflects the nation's great determination to promote data as an asset.

For data to be defined as an asset, data rights confirmation is key. A framework for data rights confirmation needs to be established at the national level or above and must be enforceable. We must learn from experiences and lessons in Europe, which found it difficult in practice to separate personal data and non-personal data in data sets under the GDPR framework, and the United States, which placed personal data under a traditional privacy framework supplemented by industry-specific laws to form a relatively flexible data rights confirmation system. In China, we recommend focusing on following the four "musts" in terms of data rights confirmation. 1) Full consideration of the different phases of digitization and particular national conditions. 2) Adherence to red-line concepts of personal privacy and sensitive data. 3) Make data flows and share the main purpose. 4) Empower data rights confirmation through digital technology such as Blockchain and Secure Multi-Party Computation (MPC). This data rights confirmation issue requires the government to provide regulatory guidance and enforcement. The Index System is a great first step in promoting the confirmation of data rights. 
Similarly, government guidance is needed to form a pricing recommendation mechanism for data assets to have expected future benefits, which is the core link to releasing the value of data assets. The valuation of data assets includes four dimensions for consideration, including application, cost, quality and risk. The value of data lies in its integration with different application scenarios, which leads to different pricing. Costs affect the value of data as well as data application scenarios. The quality of data, including its accuracy, authenticity and completeness affects data application and valuation. The value of data is affected by compliance risk, geopolitical risk and cybersecurity risk. Currently, there are three publicly recognized pricing models for assets, including the cost method, income method and market method. They each have their own pros and cons, and relevant entities can choose one model based on their actual situation and demands. Additionally, the industry is also exploring new pricing methods, including the studying of the valuation model for intellectual property rights.

To address the issue of an inexhaustible supply of data assets, new business models are needed for personal data collection, management and usage, standardize valueadded services and transactions of personal data, and protect the privacy and security of user data. With the gradual clarification on data rights confirmation and data pricing methods in China, the economic value of data will be released through a series of business models including data platform transactions, data banks, data trusts and data intermediaries that connects government, businesses and consumers. Our view is that the data platform transaction model will continue to gain momentum and become a key business model for data flows. Government-led data exchange models have already emerged in cities with an active data ecosystem such as the Global Big Data Exchange in Guiyang and the Shanghai Data Exchange Center. This platform provides a transaction platform that bridges data supply and demand and is supported by professional third-party technologies and government supervision, to eventually promote transactions and flows of data. This model resolves the main issues of mutual trust of data, data protection, and data supply and demand, and is conducive to a large number of industries developing data labeling and products through platform accumulation.

Additionally, in the process of building a balanced data asset ecosystem, the Chinese government is tackling issues including data usage tolerance and data transparency, data discrimination, and data inclusion by issuing laws and regulations, and piloting initiatives to utilize the value of public data resources. This includes connecting 18 Shanghai based commercial banks with the government's open data platform to help reduce costs in the credit business and improve business efficiency. ${ }^{11}$

Globalization 3.0 is fundamentally an exchange across national borders in data, information, technology and finance. A balanced data asset ecosystem can release the value of data and allow data to be the driving force behind Globalization 3.0. We believe that China has begun laying the groundwork for an improved ownership

\footnotetext{
${ }^{11} \mathrm{PwC}$ CN, November 2020. Data asset ecosystem white paper.

https://www.pwccn.com/en/services/consulting/publications/white-paper-on-data-asset-eco logy-nov2020.html.
} 
rights system of data through policies and regulations, exploring business models of data assets through enterprise innovation, implementing data inclusion through social forces and establishing a management and application system for data assets based on technical specifications. This puts China in a leading position in establishing a balanced data asset ecosystem, which will become a key driver for this new chapter of globalization.

\section{Conclusion}

In recent decades, with the advancement of technology and the explosion of data, we've seen the world transition from Globalization 1.0 to 2.0, and now into Globalization 3.0. The exchange between nations globally has evolved from physical goods to more intangible products such as education, healthcare and culture, to now an exchange focused on data, information, technology and finance. We believe that China and Chinese enterprises, including more than just China's tech giants, have been given the opportunity to play a leading role in this era of globalization. These opportunities lie in the three key themes discussed.

Firstly, leveraging its leading position in the global supply chain, along with the RCEP and the Belt Road Initiative, China is poised to help reshape and digitize global supply chains, creating cost efficiencies and stronger interconnectivity between nations around the world. Secondly, with sustainable development and climate change already a global mandate, China's commitment to reach carbon neutrality by 2060 will have the greatest impact in reducing carbon emissions among all nations. Chinese companies are positioned to guide upstream and downstream companies in their supply chains as well as partner with companies on this journey to ensure the goal of limiting global temperature increases to $1.5^{\circ} \mathrm{C}$ by 2100 . China has already extended support to other nations to reach the UN's 17 SDGs and will continue to actively play a role in globalizing sustainable development. Thirdly, China is on its way to building a balanced data asset ecosystem that fully releases the value of data. And data is the essential resource that fuels Globalization 3.0.

As more and more Chinese enterprises recognize these themes, trends and opportunities, we believe that more of the benefits from globalization can be captured and shared worldwide. It's time for all enterprises with strategic thinking to embrace Globalization 3.0 and play a part in shaping this exciting new era. 


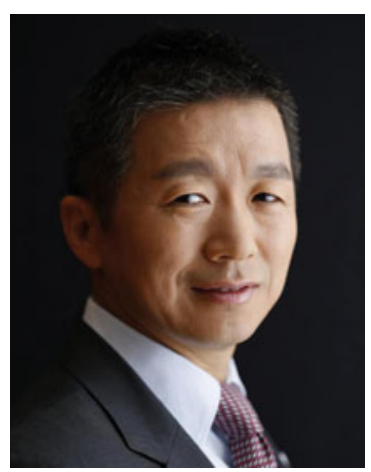

James Chang is PwC China Regional Economic Clusters Managing Partner, a member of the PwC Mainland China and Hong Kong Management Board. He is responsible for the Regional Economic Clusters business in China, the South Markets' strategy and activities, and the overall operations of the Shenzhen office. He is committed to promoting the integrated and coordinated development of China's city clusters. James has over 25 years of experience in professional services and is often invited to deliver speeches on China's economic development and transformation, green finance, data assetization and other hot topics. He is an expert consultant or member of organizations such as the National Engineering Laboratory of Big Data Distribution and Exchange Technologies and the FinTech Cooperation Committee of Asian Financial Cooperation Association.

Open Access This chapter is licensed under the terms of the Creative Commons AttributionNonCommercial-NoDerivatives 4.0 International License (http://creativecommons.org/licenses/bync-nd/4.0/), which permits any noncommercial use, sharing, distribution and reproduction in any medium or format, as long as you give appropriate credit to the original author(s) and the source, provide a link to the Creative Commons license and indicate if you modified the licensed material. You do not have permission under this license to share adapted material derived from this chapter or parts of it.

The images or other third party material in this chapter are included in the chapter's Creative Commons license, unless indicated otherwise in a credit line to the material. If material is not included in the chapter's Creative Commons license and your intended use is not permitted by statutory regulation or exceeds the permitted use, you will need to obtain permission directly from the copyright holder.

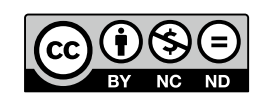

